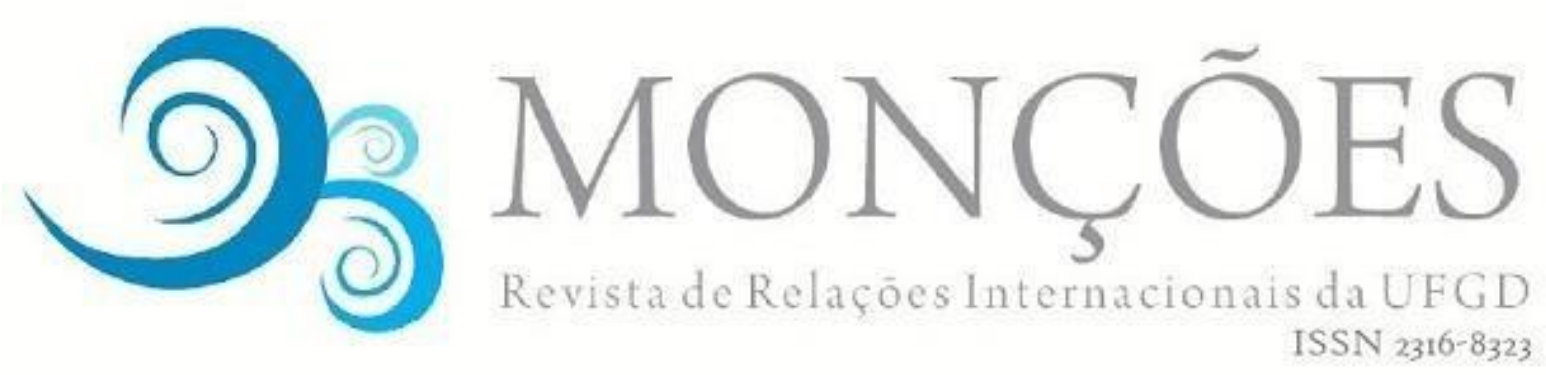

FRONTEIRA, PARADIPLOMACIA E DESENVOLVIMENTO1

TITO CARLOS MACHADO DE OLIVEIRA

Geógrafo. Doutor em Geografia FFLCH/USP, 1994. Professor do Mestrado em Estudos Fronteiriços (UFMS) e do Mestrado em Fronteiras e Direitos Humanos (UFGD). Pesquisador do Centro de Análise e Difusão do Espaço Fronteiriço (CADEF/UFMS).

RAINNE FEITOSA DO NASCIMENTO Analista de Relações Internacionais. Mestre em Estudos Fronteiriços (UFMS)

RESUMO: A intenção deste texto é discutir a paradiplomacia como um instrumento de aproximação e cooperação fronteiriça, contribuindo para a interação social e o desenvolvimento. $O$ objeto de investigação é o Projeto MS Sem Fronteiras, (uma iniciativa que mobilizou agentes públicos e privados na fronteira do Brasil com a Bolívia e com o Paraguai), sua atuação e seus desdobramentos. Como metodologia assentada em fontes documentais e entrevistas, abordou-se a atuação e os desdobramentos de um projeto com intenções paradiplomáticas de desenvolvimento do território fronteiriço. É parte do Projeto "Polos Geográfico de Ligação" com financiamento do CNPq e Fundect.

PALAVRAS-CHAVE: Fronteira; Paradiplomacia; Projeto MS Sem Fronteiras; Desenvolvimento.

\title{
BORDER, PARADIPLOMACY AND DEVELOPMENT.
}

\begin{abstract}
The aim of this text is to discuss the paradiplomacy as an approach and cross-border cooperation instrument, contributing to the social interaction and the development. The object of investigation is the MS Without Borders Project, (an initiative which mobilized public and private agents in border region of Brasil with Bolivia and Paraguay), its operations and its unfolding. The methodology is based in documental sources and intervews and the study discusses the operations and unfoldings of a project with paradiplomatic intentions of development at cross-border region. It's part from "Geografic Polar Connections" Project supported by CNPq and FUNDECT.
\end{abstract}

KEYWORDS: Frontier; Paradiplomacy; MS Without Borders Project; Development

\section{Introdução}

A paradiplomacia, até mais que a própria diplomacia, é uma arte. Um conjunto cada vez maior de atores sociais e instituições se engajam em um emaranhado sistema de cooperação internacional que transcende e desconserta as diversas

\footnotetext{
${ }^{1}$ Como parte do Projeto "Polos Geográficos de Ligação" financiado pelo CNPq e Fundect.
} 
instâncias burocráticas. Verdadeiros artesãos costuram um tecido de relações cotidianas que, de diversas formas e formatos, conformam intenções e interesses pessoais, competições empresariais e oferecem oportunidades alternativas à cooperação sócio institucional, muito especialmente nas regiões de fronteira.

A cooperação internacional tem sido utilizada, cada vez mais, para promover o desenvolvimento "desde abajo" por meio da atuação de atores locais, ainda que o ator estatal continue se postando como agente central no processo decisório. Podese afirmar que há, no território fronteiriço, uma nova conjunção de fatores que permitem que novos arranjos institucionais (públicos e privados) sejam criados, recriados e oferecidos como possibilidades de atuação para busca de objetivos específicos que nem sempre se ajustam aos desígnios da nação - e, quase sempre, de curta duração.

Nesse contexto, as fronteiras, geralmente carentes de políticas públicas, constroem oportunidades de atuação internacional por meio de seus atores locais com o incremento de ações compartilhadas em ambos os lados da regeres fine, a fim de atender anseios, interesses, oblatas e demandas específicas. Para tanto, destaca-se uma série de desígnios, ações e projetos de interações binacionais nas regiões de fronteira dado por um conjunto de atores, entidades, organismos e instituições cada vez maior, que, de forma geral, destravam as malhas (de circulação), redimensionam os nós (de intermediação) para novas atribuições e perspectivas e, concomitantemente, abonam as redes (de cooperação, de colaboração ou de competição) para novas oportunidades de criação, vitalização e redimensionamento.

O intuito deste texto é abordar o tema da arte da paradiplomacia como um instrumento de aproximação em uma região de fronteira, especificamente na conurbação de Ponta Porã-Pedro Juan Caballero na fronteira do Brasil com o Paraguai e a conurbação de Corumbá-Puerto Quijarro-Puerto Suarez na fronteira do Brasil com a Bolívia.

Nesta perspectiva, este estudo propõe expor uma análise qualitativa, documental da realidade e das práticas de cooperação internacional promovidas pelos atores subnacionais na fronteira do Brasil com a Bolívia e o Paraguai nas raias internacionais do Estado do Mato Grosso do Sul (MS) tendo como parâmetro as dimensões teóricas da ciência geográfica. 
Contudo, na labuta do real, buscou-se o (emblemático) exemplo do projeto MS Sem Fronteiras como objeto de verificação e apreciação crítica. A finalidade é suscitar um debate sobre o fenômeno paradiplomático com alusão ao tema de desenvolvimento (local, se possível!) assentado em um projeto meticulosamente construído e implementado pelo Sebrae/MS nas duas fronteiras aludidas. Em síntese, a proposta é, a partir do exemplo, refletir sobre como as ações pontuais de paradiplomacia atualmente desenvolvidas na fronteira podem ser pensadas ou definidas como promotoras do desenvolvimento.

\section{A Paradiplomacia como instrumento}

A incapacidade do Estado em alcançar o desenvolvimento de forma equânime e sustentável tem suscitado novas perspectivas de atuação externa dos atores locais em busca do desenvolvimento e amenização dos desequilibrios territoriais. Dentre esses atores, estão os governos subnacionais que, por meio das atividades, aqui entendidas como paradiplomáticas, têm conquistado legitimidade nas relações internacionais a miúde. É oportuno reforçar que este não é um evento recente, mas que adquiriu proporção significativa a partir dos anos de 1990, dada a intensificação dos processos de globalização e de suas vertentes².

O termo paradiplomacia foi empregado, pela primeira vez, pelo basco Panayotis Soldatos para discutir a respeito das atividades internacionais realizadas pelos entes subnacionais de diferentes Estados. Observa-se que os primeiros registros de atividades de paradiplomacia podem ser vistos nas relações comerciais e indenitárias realizadas por Quebec e Paris em 1882 (MICHELMANN; SOLDATOS, 2001). Embora pareça implicar a atuação paralela dos governos subnacionais frente às instâncias dos governos centrais responsáveis pelas relações internacionais, Duchacek afirma que a paradiplomacia indica uma capacidade subsidiária, referindose às ações externas complementares dos governos subnacionais para busca de interesses locais.

Para melhor compreensão deste fenômeno internacional:

\footnotetext{
${ }^{2}$ Como a democratização, a liberalização econômica e os diversos moldes e processos de integração regional, etc.
} 
A paradiplomacia pode ser definida como o envolvimento de governos nãocentrais nas relações internacionais por meio do estabelecimento de contatos, formais e informais, permanentes ou provisórios (ad hoc), com entidades estrangeiras públicas ou privadas, objetivando promover resultados socioeconômicos ou políticos, bem como quaisquer outras dimensões de suas competências constitucionais. (CORNAGO PRIETO, 2004, p. 251)

Na maioria dos casos, a paradiplomacia possui objetivos econômicos tendo o comércio como centro ${ }^{3}$. Contudo, também é utilizada para a projeção de autoridades locais; busca de soluções bilaterais parciais; missões políticas; internacionalização de empresas locais; promoção das dinâmicas migratórias e fluxos turísticos; estímulo ao compartilhamento de serviços; busca de mercados alternativos; solução para problemas ambientais, entre muitas outras das motivações que alimentam a utilização da paradiplomacia como instrumento de atuação localizada.

Como o interesse é localizado e as ações são localizadas, a paradiplomacia também se inscreve na condição local. Ou seja, normas, condutas, práticas, procedimentos, entre outras, da atuação paradiplomática também respaldam uma atuação private conversation em cada localidade. Assim, a paradiplomacia se posta como produto da condição regional da articulação entre atores e instituições regionais.

Também existem iniciativas paradiplomáticas ambiciosas para projeção dos entes subnacionais no ambiente internacional baseadas em estratégias inovadoras. $\mathrm{Na}$ região de Flandres (Bélgica), por exemplo, os objetivos das práticas paradiplomáticas estão voltados para a atração de investimentos estrangeiros e aumento significativo de suas exportações ${ }^{4}$. Em termos de projeção global, os grandes centros urbanos possuem um impacto ainda mais significativo nas relações internacionais, tornando-se polos de alta capacidade de concentração financeira e empresarial. Tóquio, Nova York e Londres possuem tais modelos arrojados de paradiplomacia constituindo verdadeiras "cidades globais" (RIBEIRO, 2009). É válido destacar que, mesmo desenvolvendo atividades paradiplomáticas com objetivo de

\footnotetext{
${ }^{3}$ Bons exemplos são os investimentos realizados na infraestrutura para a criação do corredor que liga os centros de Quebec e Nova York para intensificar suas relações comerciais. As relações comerciais entre Quebec e Paris realizadas desde 1889. (DUCHACEK, 2001; RIBEIRO, 2009).

4 Les régions ou les villes agissent comme centre d'innovation. Elles se concurrencent pour gagner les investissements privés et la localization de centres de decisions. Cett concurrence créatrice encourage l'innovation, iéfficaité, la mobilization collective, mais aussi les conflits entre les regions et les villes dún meme pays. (PAQUIN, 2004, 39).
} 
alcançar influência global, nenhuma atividade paradiplomática possui personalidade jurídica internacional definida, posicionando a sua incapacidade de realizar tratados, acordos internacionais ou práticas que possam ferir a ordem e soberania nacional.

A paradiplomacia também não está restrita a alianças entre o setor público, senão muito o contrário, comumente se constroem parcerias que embaralham interesses públicos e privados. Nestes termos, as possibilidades de articulação entre empresas, governos e demais segmentos dentro da modalidade de cooperação internacional revelam novas estratégias de atuação possíveis em que a paradiplomacia alonga ser oportuna para o desenvolvimento da localidade; possui ainda fins diversos e adquire características peculiares segundo as motivações das regiões onde são praticadas e seu caráter dinâmico lhe confere um leque de temas os quais dificilmente conseguiriam receber tratativa pela política externa de seus Estados. Por este motivo, ela torna-se uma ferramenta oportuna para a elaboração de políticas para o desenvolvimento das regiões de fronteira com base na cooperação descolada dos rígidos padrões estabelecidos pela tradicional diplomacia.

\section{A fronteira e a paradiplomacia}

Mais que tudo, a paradiplomacia deve ser entendida como uma das inúmeras ferramentas disponíveis aos atores locais para a promoção do entrelaçamento e desenvolvimento na região de fronteira; está posta na agenda daqueles territórios e seus resultados, ainda que variados, têm sido satisfatórios, inda que pouco divulgados.

Nota-se de forma mais detalhada que a paradiplomacia adquire características peculiares adaptadas à realidade da fronteira que não são, a priori, direcionados para a conquista de importância global reforçando a ideia de que a paradiplomacia apresenta especificidades segundo a região em que é praticada. Vale ressaltar que dentro do escopo de integração regional, a paradiplomacia é vislumbrada como uma etapa de aprofundamento das relações de cooperação cf. Oddone e Vázquez (2015) destacam que as relações transfronteiriças possuem um papel estratégico nesse processo por prospectarem níveis de interação mais 
elevados tornando-se núcleos de experimentação para que se caminhe rumo ao estreitamento das relações entre os Estados partes.

Por outro lado, uma das principais características da paradiplomacia é seu estilo fortemente volátil quanto aos seus objetivos - dificilmente sobre ela se estende um manual de conduta e concepções - mais fortemente ainda no ambiente fronteiriço.

No mesmo sentido, sobre as fronteiras incide um comportamento transversal, versátil, poroso, com deslizamentos, cuja relação com o "outro" é tanto de alteridade quanto de acolhimento, de todo modo que se trata de um território singular onde o funcionamento do espaço geográfico está carregado de anfibologias e imprecisões.

As fronteiras, por sua vez, assim como a paradiplomacia, são inconstantes e de incongruentes mutações. Talvez, até por assim ser, o território fronteiriço e a paradiplomacia possuam capilaridades intrínsecas com design apropriado para estabelecerem práticas e experiências evidenciadas com detalhada avaliação expost.

De maneira geral, é possivel observar que sobre as fronteiras existem três condicionamentos que, diferentemente de outros lugares, subsume o território e interferem na dinâmica de suas relações setoriais.

O primeiro é a sobreposição de uma ordem mundial que dita a velocidade e o quantum dos fluxos globais de capitais sobre elas, fronteiras. Sendo as fronteiras os pontos nodais de materialização destes fluxos, a agilidade (ou lentidão) imposta leva, inopinadamente, a ascender ou a recrudescer a vida econômica do lugar, com poder de tanto engendrar novas e saudáveis práticas cotidianas, novas e destacadas funções regionais, como novos e perigosos riscos capazes de macular o território; pode-se afirmar que interfere diretamente na dimensão produtiva do território fronteiriço. A aposição derivada dos fluxos mercantis desta ordem dá-se sempre mediante a combinação de legislações previamente acordadas, o que, noutros termos, desestimula o intercâmbio paradiplomático.

Após o início deste século, especialmente depois dos acontecimentos do 11 de setembro nos EUA, há um recrudescimento do discurso de globalização econômica de um "mundo sem fronteiras". Tal fato vem afetando inadvertidamente as fronteiras: se antes havia uma perspectiva de dinamização de todos os territórios com maior contato (um tipo de debordering), agora, há um manifesto de seletividade 
com delimitações programadas elegendo determinadas fronteiras como pontos-eixos por onde é possível convergir um "trânsito monitorado" para um fluxo seguro de mercadorias. Esta condição tem prestigiado determinadas lindas - tipo UruguaianaPasos de los Libres e Corumbá com Puerto Quijarro - e enfraquecendo um conjunto de outras cidades fronteiriças. Uma espécie de rebordering (fechamento) vem se fortalecendo e reverberando para outros territórios fronteiriços.

Em outro lado, as fronteiras - brasileiras, sobre muito - estão sob a égide da condição de serem latino-americanas. Ou seja, há sobre elas uma conformação latino-americana de consistência assaz complexa, cuja abordagem conduz necessariamente à determinação de possuir multiculturalidade, descompassos éticos, contradições geopolíticas e interesses nacionais divergentes, suscitando simultaneamente coesão e conflitos, desigualdade e insegurança, instrumentos constituintes da dimensão sócio cultural e política do território.

Tal conformação impacta decidida e decisivamente sobre todos os fatos e atos que ocorrem nas fronteiras: quão mais habitadas estiverem mais fortes serão suas expressões. Os padrões que as regem são os axiomas dados pela afluência de culturas, conflitos, processos e pactualidades que arranjam sua condição geográfica. Ponta Porã com Pedro Juan Caballero refletem sintomaticamente, até hoje, os reflexos da Guerra do Paraguai (palco de sua finalização), assim como o fato do Paraguai ser grande produtor de cannabis sativa; da mesma forma, a fronteira de Corumbá com Puerto Suarez e Puerto Quijarro respondem pela condição da Bolívia ser um estado plurinacional, e também daquela nação ser o terceiro maior produtor de cocaína do planeta. No âmbito destas sensíveis relações onde se alargam os horizontes diplomáticos, a paradiplomacia também acha terra fértil para interações à miúde que aparecem com menor ímpeto.

E por fim, um processo de fronteirização $0^{5}$ convergente - posicionado pela dimensão territorial e produtiva da fronteira. Trata-se de um procedimento contínuo de interação social e intercâmbio econômico, cooperação, inclusão e exclusão. Acontece enquanto "fronteira como instituição" (NEWMAN, 2006), ou quando se caminha na destruição da condição "alienada" e sustenta formas de

\footnotetext{
5 “Fronteirización designa los processos hostóricos a trav's de los cuales los diver sos elementos de la frontera son construídos por los poderes centrales y por las poblaciones locales. (...) Entonces, el proceso de fronteirización se transforma, pero no termina" (GRIMSON, 2003 p 17, 18-grifo no original)
} 
"interdependência", "coexistência" e "integradas" - emprestando as categorias de Martínez (1994) - ou, quando sai da posição de "distante" ou "protocolar" para a posição de "vibrante" conforme categorias de Oliveira (2015a).

Aqui, este termo possui similitudes com a transfronteirização aludida por Rückert, Campos, Superti e Porto (2014 p. 102), entendidas “...como diferenciações territoriais emergentes [...] entendidas como mutáveis, móveis e fluidas que passam por constantes processos de abertura/fechamento ("debordering /rebordering)".

Este processo possui internamente um conjunto de vantagens e confere à fronteira uma condição especial que, inclusive, sobrepõe com extraordinária diferença em relação aos outros ambientes não fronteiriços. É este processo de fronteirização que consolida na fronteira (conurbada ou semi-conurbada, casos das fronteiras aqui estudadas) que haverá sempre um dos lados como agente dinâmico, propulsor do desenvolvimento, enquanto o outro lado sempre se posiciona como agente consorciado. Por mais que haja uma crise que abarque as duas nações das cidades fronteiriças, assim como por mais que o crescimento esteja posto às nações simultaneamente, as assimetrias e o processo de fronteirização do lugar sempre possibilitarão que um lado da fronteira esteja mais dinâmico em relação ao outro. Esses lados se alternam em consonância com os abalos provocados, em especial, pela lógica conjuntural'.

Sobre todas essas peculiaridades apresentadas pelos territórios fronteiriços, a paradiplomacia passa a ser um recurso viável para tratar dos problemas, impulsionar capacidades e negociar conflitos, numa perspectiva de performance em um espaço de paisagem confluente com sua condição ${ }^{7}$.

O desenvolvimento local é incapaz de ser promovido apenas por um agente e, em se tratando de fronteiras, (especialmente aquelas conurbadas), é imprescindível a comunicação entre os atores territoriais de cultura, língua, leis, comportamentos diferentes, no sentido de compartilhar aspirações e ações que

\footnotetext{
6 Enquanto a conjuntura eventualmente interfere no cotidiano não-fronteiriço, na fronteira seu impacto é imediato; confere Pébayle (1994) que esta lógica conjuntural (câmbio, acordos bilaterais, crise política, etc.) é quem possibilita o verdadeiro dinamismo da região de fronteira. A conjuntura coloca-se, desta forma, como elemento indispensável para caracterizar e depreender o processo de fronteirização, a conformação latinoamericana e os impactos da ordem mundial.

7 “As características locais da fronteira se tornamo aspecto dominante da paisagem cultural local. A paisagem de fronteira é uma parte do paradigma paisagem-territorialidade. Na verdade, o conceito de paisagem surge do percebido, ...” (SANGUIN, 2015 p 390).
} 
impulsionem o desenvolvimento da localidade. Nessa perspectiva, a paradiplomacia apresenta-se como ferramenta a serviço da cooperação para o desenvolvimento, tendo em vista a necessidade de existir um núcleo de atores locais representados por ambos os lados da fronteira, utilizando o poder por meio do consenso mútuo para sensibilização e conversão de esforços em ações que atendam as demandas locais.

Nas regiões de fronteira, a paradiplomacia costuma ser utilizada para atender objetivos típicos de uma região carregada de contradições, geralmente marcada pela insuficiência ou ineficácia das políticas públicas.

Contudo, o fato de existirem relações paradiplomáticas na fronteira em maior ou menor medida não significa, necessariamente, que estas visem ao desenvolvimento propriamente dito ${ }^{8}$; podem ser, simplesmente, um instrumento para intensificar as externalidades de proximidade (Cf. TORRE, 2003), ou estabelecer parâmetros associativos de convivência. À guisa de exemplo, acordos paradiplomáticos, que não possuem relação direta com uma proposta de desenvolvimento, foram aplicados com algum êxito nas fronteiras estudadas, tipo: "Acordo Fronteira Limpa"9; "Projeto Revitalização da Linha Internacional"10; Programa de Preservação das Águas Internacionais do Rio Apa"11, além de acordos de cooperação entre as instituições fazendárias (para desembaraço aduaneiro) e

\footnotetext{
8 "Atualmente, a paradiplomacia transfronteiriça regional manifesta-se por vários contatos de cooperação de migrantes e imigrantes na linha de fronteira; o movimento legal de bens manufaturados; prevenção do contrabando; as transferências de bens roubados, tráfico de drogas e compras excessivas pela fronteira [...]; a gestão dos recursos hídricos; problemas de poluição [...] transferências de energia (gás e energia hidrelétrica entre Quebec, New York, e os estados da Nova Inglaterra); Defesa Civil; esgoto; prevenção de desastres naturais como os incêndios em florestas localizadas na fronteira ou cidades gêmeas, e inundações; bens manufaturados e / ou empreendimentos ecológicos tal como se configura a estrutura cooperativa trasnfronteiriça [...] Todos esses acordos formais e informais são claramente resultantes de um novo e crescente reflexo da permeabilidade das fronteiras das soberanias nacionais" Tradução acadêmica de DUCHACEK, 2001, p.20.

${ }^{9}$ Entre a Prefeitura de Corumbá e a Alcaldia de Puerto Quijarro, que visava promover uma cooperação para limpeza urbana em ambas as cidades como forma de promover um combate mais incisivo ao mosquito da dengue; como desdobramento, outro projeto de pouco sucesso foi de combate à leishmaniose e raiva canina.

${ }^{10}$ Projeto da Prefeitura de Ponta Porã com a Intendência de Pedro J. Caballero, financiando pela União Europeia que possibilitou uma nova arquitetura para abrigar camelôs e casilleros na linha que divide as duas cidades.

${ }^{11}$ Projeto firmado entre Gavernación del Departamento de Amambay e a Prefeitura de Ponta Porã, também financiado pela União Europeia, que visou criar mecanismos de preservação e criar formas alternativas de utilização de suas potencialidades para população ribeirinha (OLIVEIRA, 2012).
} 
pactos estabelecidos dentre as forças de segurança e defesa para compartilhamento de informações e ações programadas, entre outras ${ }^{12}$.

Existem ainda muitos obstáculos que desafiam o avanço das práticas paradiplomáticas: falta de fomento dos governos centrais para impulsioná-las, falta de qualificação de pessoal e planejamento estratégico que sobreviva às alternâncias de governo; o baixo nível de autonomia dos governos locais e regionais, ou ainda a dificuldade de institucionalização efetiva das práticas. A carência de uma estrutura política especializada com gestores capacitados para este fim também reflete na ausência de uma política que perdure às alternâncias de governo e atitudes, além da escassez de informações a respeito das experiências paradiplomáticas praticadas na fronteira que poderiam estar compartilhadas; também há, ainda, receios com possíveis ilegalidades por parte dos agentes locais, dificultando um acompanhamento-monitoramento e uma análise mais crítica dos resultados alcançados por essas iniciativas.

O próprio histórico de naturais rivalidades e preconceitos entre as sociedades de cada lado da fronteira tende a comprometer uma "cooperação entre instituições" de largo prazo, ou seja, os intentos paradiplomáticos, no geral, possuem "fôlego curto", dimensões restritas e aplicabilidade condicionada ${ }^{13}$. Embora ambos os lados desfrutem do processo de fronteirização - o que permite que um lado tenha natural interesse na melhoria das condições socioeconômicas do outro, o que favoreceria, mutatis mutandis, envolver o seu lado nos avanços do outro - o envolvimento de atores (e/ou instituições) de um lado em ações no outro lado é quase sempre observado com desconfiança, receio e dúvida por ambos, mesmo assim: acontece!

\section{O desenvolvimento (local) e as perspectivas de atuação dos atores locais na região de fronteira.}

Nunca é demais lembrar que até muito pouco tempo passado (até metade dos anos oitenta do século passado), tanto a fronteira em tela - assim como as

\footnotetext{
${ }^{12}$ Cabe ainda lembrar as ações chanceladas pelo HABITAT (Organismo das Nações Unidas para assentamentos humanos) em Ponta Porã para auxiliar na realização do Plano Diretor Participativo com Consulta Urbana e um Plano de Ação com vários outros desdobramentos incluindo Pedro Juan Caballero.

${ }_{13}$ As cooperações paradiplomáticas, no geral, se dão mediante assunto específico, pontual em condições extremamente pragmáticas e, somente assim, têm se mostrado um instrumento eficaz.
} 
demais - era marcada pelo trinômio segurança-soberania-desenvolvimento (nesta ordem) onde: a segurança estava associada, praticamente, à condição de "defesa" ou de militarização; a soberania estava sob o escudo da doutrina da "intocabilidade" do território; e o desenvolvimento, enquanto último elemento, somente era permitido no sentido top-down.

Sob esta condição, regiões de fronteira estavam submetidas a um certo distanciamento proposital do restante da Nação. Os projetos nacionais de desenvolvimento sequer se direcionavam para as regiões fronteiriças; havia um retardamento tácito e proposital da expansão da infraestrutura e da comunicação e qualquer "articulação local" era vigiada e controlada ${ }^{14}$. Não apenas as instituições, mas também os atores locais viam-se manietados, acautelavam-se sob qualquer possibilidade de aproximação explicita com o país vizinho. Sob estas condições, abriam-se frechas para formação de grupos (ou unidades) de controle com motivações duvidosas; mas também abriam-se pertinentes possibilidades de arranjos criativos e subversivos de aproximação.

Tendo como base os pressupostos do tempo social de Boudieu (2001 e 2005), localizavam-se, por assim dizer, as fronteiras em um tempo histórico diferente ao do restante do Estado-Nação. Tão somente a partir dos anos oitenta, mais incisivo no final da década (com a nova Constituição), é que se inicia um processo ainda em curso - de ruptura dos conceitos aos elementos atribuídos ${ }^{15}$, enquanto um novo reposicionamento, trocando de lugar o desenvolvimento, ${ }^{16}$ passa a ser edificado.

Sobreposto ao dito, o mundo muda e o Brasil também. O aumento dos fluxos internacionais estabelecendo um novo ritmo às economias periféricas, a derrocada da tradicional e resistente trincheira inflacionária, o início da internacionalização da economia brasileira, entre vários outros elementos, passaram a corroborar com

\footnotetext{
14 Conta um antigo prefeito de Ponta Porã que "até para asfaltar uma rua eu tinha que informar ao coronel de plantão" (a garantia de responsabilidade pela afirmação é nossa).

15 A segurança foi definitivamente separada do conceito de defesa; a soberania abandona a intocabilidade e se avizinha mais da "vontade geral" de Rosseau e o desenvolvimento passa a ser conferido como possibilidade bottom-up.

16 É quase consenso (exceto para mídia populista) de que o desenvolvimento é verdadeiro garantidor de maior segurança e defesa do território; hipoteticamente ao trinômio anterior, hoje postar-se-ia: desenvolvimentosegurança-soberania, onde a palavra subsequente se subsume à anterior.
} 
novos conceitos e novas atitudes em relação à condição fronteiriça e ao desenvolvimento.

Se fronteira é, doravante, recolocada sob a lógica de um novo paradigma da circulação global, visto que é por ela que os fluxos se materializam conquanto relação ao desenvolvimento, os questionamentos teóricos caminharam substantivamente em direção a um novo conceito de gestão e de poder decisório sobre as ações realizáveis, justamente porque a crise do modelo centralizador ocorre na medida em que se iniciava uma pressão por autonomia baseada numa redistribuição de poder por parte dos atores locais. E a atuação desses atores passa a proporcionar alternativas que fogem do aparato regulador tradicional.

Esse processo de mudanças perpassa não apenas pela redefinição do papel do Estado e suas instâncias governamentais ou subnacionais com aquisição de novas responsabilidades, como também implica na amplificação do espaço geográfico na perspectiva da totalidade social, no território como vetor do desenvolvimento de "... un conjunto de actores (empresarios, instituciones públicas, sindicatos, asociaciones privadas con fines diversos...) con capacidad de decisión, que se identifican con esse espacio y son capaces de tomar decisiones y abordar proyectos de futuro." (BOISIER, 2001 p. 39).

É nesta perspectiva que se abriram lacunas para a consecução de teorias tipo desenvolvimento local. Onde, segundo a OT (Organização Internacional do Trabalho, 2002), se estabelece de maneira compartilhada e participativa com capacidade de pactos, nexos contratuais entre instituições e atores sociais para, assim, impulsionar iniciativas locais com visibilidade e perspectivas de continuidade.

Desta forma:

En términos generales, el desarrollo local implica la concertación entre los
agentes - sectores y fuerzas- que interactúan en un territorio determinado
y la participación permanente, creadora y responsable de ciudadanos y
ciudadanas en un proyecto común de diversas dimensiones. (...) El fin del
desarrollo local es elevar la calidad de vida de cada ciudadano y ciudadana
que viven en ese territorio, contribuir al desarrollo del país y enfrentar
adecuadamente los retos de la globalización y las transformaciones de la
economía internacional. (GALLICCHIO e CAMEJO, 2005 p.40)

Como percebido, o termo em voga pressupõe duas palavras: o consenso e o poder (BOISIER, 1999). Isto é: a articulação de atores locais com competência e capacidade de poder decisório para criar novas instituições e planos com ênfase na 
promoção do capital humano. Para tanto, há necessidade de coordenação entre a política nacional de desenvolvimento com a política local e que haja congruência entre ambas para se chegar ao consenso e poder.

No entanto, as mudanças implicam uma série de readequações que, por vezes, esbarram-se em resistências, justamente porque é necessário um redimensionamento do papel a ser desempenhado pelos atores locais e a reversão de uma cultura de dependência externa podendo implicar em longo período de adaptação e assimilação de uma estrutura mais autônoma.

Essa resistência pode ser observada na região de fronteira do Brasil com a Bolívia e Brasil com o Paraguai. Como visto acima, as fronteiras além de apartadas dos projetos nacionais estavam sob o signo de (uma espécie de) apart-nation. $\mathrm{Ou}$ seja, as aproximações eram malvistas, monitoradas, vigiadas e - por vezes punidas. Os fronteiriços daquelas localidades tiveram, então, que reaprender, ou posto melhor: passaram a expor um complexo desembaralhar de um conjunto de arranjos criativos de aproximação que vão de ações simples como a dupla cidadania, a utilização coletiva de serviços e a contratação ilegal de trabalho até as sofisticadas combinações de repasse de energia, a receptação de mercadorias, etc. $E$, quando essas debilidades são presentes na região, as iniciativas locais com características paradiplomáticas podem abrir novos caminhos com possibilidades de atuação que podem ser aproveitadas e amplificadas.

\section{O Projeto MS Sem Fronteiras - um caso}

A iniciativa da "Integração Competitiva de Micro e Pequenas Empresas em Ambiente de Fronteira - Bolívia, Brasil e Paraguai - MS Sem Fronteiras" (2010/2014), sob coordenação do Sebrae ${ }^{17}$, envolveu agentes públicos e privados nacionais e estrangeiros. O objetivo central do MS Sem Fronteiras foi fomentar a competitividade das MPEs (micros e pequenas empresas) localizadas nos territórios fronteiriços visando fortalecer a cadeia produtiva de determinados setores a serem definidos perante um processo de diagnóstico técnico da realidade local. Teve como

\footnotetext{
17 Serviço de Apoio a Pequenas Empresas é uma entidade paraestatal com a missão de promover a competitividade e o desenvolvimento sustentável dos pequenos negócios e fomentar o empreendedorismo para fortalecer a economia nacional.
} 
elemento chave a promoção da cooperação em ambos os lados da fronteira e, como ponto de partida, a práxis de aproximação e convivência entre as cidades de Ponta Porã ${ }^{18} \mathrm{com}$ Pedro Juan Caballero ${ }^{19}$ na fronteira Brasil-Paraguai e Corumbá20, Ladário ${ }^{21}$ com Puerto Quijarro ${ }^{22}$, Puerto Suarez ${ }^{23}$ na fronteira Brasil-Bolívia.

Para planejamento e execução, a equipe foi formada por via de um Conselho Diretor - composto pelos representantes do Sebrae/MS, Sebrae Nacional, governos do Estado do Mato Grosso do Sul, Província de German Busch (Bolívia), Departamento de Amambay (Paraguai) e por um representante de cada um dos Comitês Gestores Locais. Responsável pelo papel principal dentro do projeto, ao Conselho foi delegada a função de definir a orientação estratégica, aprovar o plano anual, o balanço, o orçamento e, ainda, monitorar e avaliar os resultados das ações previstas.

Através da Unidade de Gestão do Programa (ou simplesmente UGP), composta pela equipe de profissionais selecionados pelo Sebrae, houve acompanhamento do andamento dos planos de atividades previstas. A UGP também foi encarregada de facilitar o intercâmbio entre os territórios e ainda supervisionar o trabalho das Unidades Executoras Locais (UEL). Logo, a UGP era a unidade intermediária que se reportava à Diretoria do Programa prestando relatórios das atividades desempenhadas pelas UELs. Estas últimas, por sua vez, foram compostas por representantes públicos e privados de cada Estado, as quais, além de apoiarem as UGP, tinham responsabilidade de execução das atividades dentro de sua área de atuação. De forma integrada, estas equipes trabalharam de acordo com cinco objetivos estabelecidos pelo Projeto, conforme exposto em SEBRAE, (s.d p. 5):

\footnotetext{
18 Cidade a $330 \mathrm{~km}$ de Campo Grande (capital do Mato Grosso do Sul) com 90 mil habitantes, pautada no comércio e no agronegócio.

19 Capital do Departamento de Amambay com aproximadamente 100 mil habitantes, pautada no comércio de reexportação e fronteiriço, agronegócio, ensino universitário e, mais recentemente, nas possibilidades de implantação de maquilas.

${ }^{20}$ Cidade a $420 \mathrm{~km}$ de Campo Grande, com cerca de 100 mil habitantes, pautada no comércio de export-import e fronteiriço, pecuária e mineração.

${ }^{21}$ Cidade com cerca de 20 mil habs. conurbada com Corumbá.

22 Passivelmente, a mais dinâmica cidade fronteiriça da Bolívia, pertence à Provincia de German Busch e Departamento de Santa Cruz, com cerca de 25 mil hab. Está a 560 km de Santa Cruz de la Sierra, com economia pautada no comércio esport-import e fronteiriço, localizando-se a três quilômetros de Corumbá.

${ }^{23}$ Capital da Província German Busch, com 25 mil hab., às margens da laguna Cáceres e a $11 \mathrm{Km}$ da fronteira.
} 
1. Formação de redes e desenvolvimento de capacidades - realização do mapeamento da região para compreender a dinâmica da realidade local por meio da aplicação de diagnóstico. Fase de levantamento de informações; criação de redes de cooperação, além do processo de sensibilização dos atores.

2. Acesso a serviços de desenvolvimento empresarial - ordenamento dos serviços empresariais conforme ambos os lados da fronteira após a seleção de cadeias produtivas atendidas pelo Programa, com a inclusão de setores com maiores fragilidades por meio da realização de cursos de profissionalização e capacitações.

3. Fomento ao desenvolvimento de projetos empresariais sustentáveis e inovadores - incorporação de inovações nas empresas dos setores produtivos priorizados e consolidação das cadeias de valor.

4. Desenvolvimento de bens públicos - melhoramento das condições para o desenvolvimento das atividades produtivas nos territórios selecionados a fim de promover iniciativas específicas que contribuíssem com o desenvolvimento de vantagens competitivas.

5. Monitoramento, lições aprendidas e disseminação dos resultados - registro, avaliação, disseminação e desenvolvimento de método para a réplica/expansão da experiência.

Foram investidos, ao longo de quatro anos (2011-14) da excussão efetiva do Projeto, um total de U\$2,8 milhões que atingiram 2.578 empresas, sendo 2.007 no lado brasileiro, 292 no lado boliviano e 280 no lado paraguaio. Considerando o volume de recursos aplicados, trata-se de um dispêndio relativamente baixo dado o número de empresas contempladas e os resultados quantitativos auferidos no trajeto de sua execução (pouco mais de U\$ 1,1 mil por empresa); porém, faltam ainda os resultados qualitativos sobre o acompanhamento, os desdobramentos técnicos e estudos complementares para uma conclusão mais consistente.

Outro ponto relevante do projeto também pode ser visto na constituição de redes de comunicação entre atores dos diferentes territórios como elemento fundamental quanto ao propósito de caminhar passos adiante no que diz respeito ao desenvolvimento daqueles territórios.

Cabe porquanto indagar: o projeto MS Sem Fronteiras é um exemplo de paradiplomacia para o desenvolvimento local? Ou ainda: este projeto atende ao 
conjunto de fatores que respondem às necessidades da interação fronteiriça do território aplicado? As respostas para estas indagações aqui expostas foram construídas em cima do arcabouço teórico relacionado aos relatórios produzidos pelo Sebrae/MS e algumas poucas mas concertantes entrevistas com atores envolvidos.

Dentro da cooperação internacional, existe a Cooperação Triangular, a qual está baseada numa perspectiva de horizontalidade. Ela envolve três atores com diferentes níveis de experiência, sendo: sócio doador de cooperação tradicional; sócio estratégico (emergente de cooperação) e o sócio receptor de cooperação.

O Projeto em tela foi uma cooperação técnica cujo objetivo esteve relacionado ao fortalecimento de cadeias produtivas na faixa de fronteira do Estado de Mato Grosso do Sul. A cooperação entre o Banco Interamericano de Desenvolvimento (BID) como sócio doador; Paraguai e Bolívia como sócios receptores de cooperação; e o Brasil através do Serviço Brasileiro de Apoio às Micro e Pequenas Empresas (Sebrae) e o Governo do Estado de Mato Grosso do Sul, como sócio emergente estratégico, é passível de equipará-la à modalidade de Cooperação Triangular (CTR), ponderando-se que nasceu para promover a cooperação entre países diferentes nas áreas de interesses, a priori, comuns, ao mesmo tempo em que sua trajetória pautou-se pela construção de diálogos horizontais com fixação de procedimentos ${ }^{24}$.

Não permanece dúvida, tanto de forma ampla como estrita, que o Projeto, aqui exposto, se desdobra em um desenho de cooperação paradiplomático. Então, pode-se dizer que existiu uma iniciativa ousada que apresentou passos formidáveis para a consecução de uma cooperação horizontal. No entanto, resta saber se a ação observada no conjunto da atuação do MS Sem Fronteiras fica sujeita a ser destacada como uma atividade compatível com desenvolvimento local, propriamente dito.

Assim, deve-se considerar alguns pontos nobres para identificação das formas de desenvolvimento local. O Projeto MS Sem Fronteiras por meio de nenhum documento sustenta ou direcionou as suas ações no sentido associativo, mesmo que não se excluam possibilidades de ações cooperativas e colaborativas entre as

\footnotetext{
24 Ver mais sobre Cooperação Triangular (CTR) em PINO, B.A (2013).
} 
empresas; em parte alguma está proposto, explicitamente, que seu objetivo final seja o desenvolvimento local: logo, esta associação é uma situação relacional dada pelos pesquisadores deste texto considerando as premissas e expectativas deparadas pelo trabalho de campo.

No mesmo lado, o MS Sem Fronteiras não trabalha no sentido do afastamento das empresas, entidades e instituições, senão o contrário, ainda que possua a competitividade empresarial como tema central e como princípio - fator inerente aos propósitos do Sebrae ${ }^{25}$. Ao mesmo tempo, suas pretensões estão carregadas de atos que estendem as possibilidades de criar sinergias territoriais no sentido de preparar os atores locais para aprimoramento da capacidade técnica para formular projetos e programas, permitindo, como efeito, que a economia local possa caminhar em direção à redução da dependência de ações eminentemente externas, sem, todavia, desanimar a aproximação daquele território a outros mercados ${ }^{26}$.

Uma de suas características, segundo a teoria que permeia e consolida a possibilidade de visualizar o chamado desenvolvimento local, suficientemente cristalizado pelos seus teóricos, está na capacidade de se inscrever dentro de um contorno com forma "(...) participativa, concertadora, ascendente y multidisciplinaria la que será multiactiva y ecológica, capaz de establecer nexos contractuales entre los actores sociales y las instituiciones que las representan y las apoyan." (FALCON y JARA, 2005. p.18). Grosso modo, é possível identificar quatro formas de operar o território em direção ao desenvolvimento local: um diagnóstico; uma estratégia muito transparente de formulação de um desenvolvimento alcançado via participação compartilhada; uma institucionalidade local com espírito associativo e capacidade coordenadora dos meios; a participação de entidades que possuam compromissos evidentes com os princípios democráticos, com a distribuição de rendas e a integração social e cultural; e um solidário processo de inter-relação e interação associativo (FALCÓN Y JARA, 2005).

Uma cooperação técnica tem limitações e, de fato, pode não possuir pretensões de gerar o desenvolvimento local propriamente dito. E esta experiência implementada pelo Sebrae de Mato Grosso do Sul, mesmo com clara intenção de

\footnotetext{
${ }^{25}$ O Sebrae, em princípio, não trabalhou os conceitos de cooperação e concorrência como antagônicos, mesmo que tenha deixado explicita a preferência pelas condições de concorrência.

${ }^{26}$ Uma forma qualquer de afastar (mas, não cortar) a dependência das teias armadas pelas redes subordinadas e/ou tuteladas, trabalhando aqui comos tipos de redes definidas em INOJOSA (1999)
} 
promover um fomento ao desenvolvimento do espaço fronteiriço, não se propôs a conduzir o Projeto no sentido alvitrado pelas teorias do "desenvolvimento local", cujas iniciativas bem geridas são frutos de mobilizações ainda que pequenas, funcionando como projeto piloto/núcleo e com envolvimento de atores locais desde seu embrião.

Como visto no Projeto MS Sem Fronteiras, a participação dos atores locais esteve incisivamente mais ligada às ações de execução (vide objetivo 5 do Projeto, dito acima), enquanto o conhecimento foi fruto de práxis de consultoria repassadas por empresas contratadas pelo Sebrae, substancialmente especializadas em noção estritamente técnica pouco associativa ${ }^{27}$. Este fato em si não constitui um problema quando se trata de uma cooperação técnica; na verdade, elas (empresas) atendem ao objetivo proposto de forma plena. Todavia, tratando-se de desenvolvimento local a situação não é análoga, onde há a imperativa participação de todas as partes desde a concepção, elaboração, execução e avaliação dos resultados no sentido de gerar conhecimento (em stricto e lato sensu) o mais coletivamente possível.

Outro fato importante que distancia o Projeto em tela do desenvolvimento local é a forma estrutural de operação. Como se observa, no MS Sem Fronteiras, à exceção do diagnóstico, todos os demais pontos estão distantes dos desígnios fornecidos pela orientação do desenvolvimento local.

Entretanto, o Projeto em tela é capaz de gerar desenvolvimento, inclusive local? Com capacidade de provocar desenvolvimento, sem dúvidas que sim! Com possibilidade de confluir para um desenvolvimento local, ante as metas estabelecidas, somente a história será capaz de responder.

Se, como aludido, este projeto desenvolvido pelo Sebrae/MS caminha pouco em direção a um formato de desenvolvimento no escopo teórico do desenvolvimento local; ao mesmo tempo, o volume de relações implementadas ao longo de sua execução está muito distante de se constituir em um fracasso territorial28. O Projeto executado não pode ser recusado nem descartado como um instrumento disponível ao desenvolvimento.

\footnotetext{
${ }^{27}$ Conforme se observa nos relatórios do Projeto, as empresas contratadas para esta finalidade não possuíam nem escopo, muito mesmo experiência que as qualificassem em ações de cooperação e as sociativismo.

${ }^{28}$ Considerando aqui os fatores territoriais e não os elementos da análise (objetivos e interesses) traçados pelo Sebrae/MS, por estes, sim, o MS Sem Fronteiras foi ladeado de sucesso.
} 
As parcas entrevistas realizadas com atores-chave (gerentes e proprietários das empresas envolvidas no Projeto) dão sinais evidentes de uma aceitação convincente por parte da comunidade envolvida nas ações propostas. Os dados coletados até 0 momento ainda não são suficientes para responder positiva ou negativamente sobre a consolidação eficaz dos objetivos traçados, mas é possível afirmar que tal iniciativa possui instrumentos robustos para produzir conhecimento tácito e instituir relações de confiança entre atores, subsidiar a consecução de um desenvolvimento para o território envolvido, quebrar resistências institucionais e suscitar uma aproximação ensejada aos atores econômicos e políticos - quiçá um dia alcançar uma articulação que suscite um desenvolvimento local no sentido estrito do termo.

Em síntese, o Projeto esteve focalizado no fomento de ideias - não totalmente inovadoras, por vezes até conservadoras - que possuíssem uma aplicabilidade dos resultados com efeitos amplos, isto é, para além do benefício que contemplasse apenas os envolvidos em uma cadeia produtiva específica dentro da abrangência das cidades fronteiriças dos três países. Nesse sentido, os resultados deveriam abranger as cidades dos dois lados, priorizando grosso modo a valoração intrínseca dos atores e de seus poderes na cooperação transfronteiriça alcançando, como efeito, o objetivo maior do Projeto: o "desenvolvimento integrado da região de fronteira".

O Projeto MS Sem Fronteiras, assim, apresentou-se como uma iniciativa que chama a atenção tanto pela sua capacidade de horizontalizar ações até certa medida ${ }^{29}$, quanto na capacidade de mobilizar atores numa proporção muito aceitável nas fronteiras selecionadas. Mais ainda: permite ser avaliado pela sua característica inédita de posicionar (melhor dizendo: reposicionar) recursos (humanos, sobremuito) ante as necessidades regionais para convergências de resultados empresariais efetivos - neste sentido: um ganho.

Ante aos poucos dados conquistados (via entrevistas aleatórias), se observa que este projeto plantou raízes que podem se desdobrar em substantivos intentos de aproximação e colaboração, visto que abre espaço para crescimento de alianças flexíveis no sentido de assegurar capacidade competitiva (mercantil em primeiro

\footnotetext{
${ }^{29}$ A plena horizontalidade não passa de um "fetichismo organizacional"; na verdade, ela possui severos limites como princípio organizacional hegemônico.
} 
plano) e gerar frutos capazes de retroalimentar as articulações territoriais horizontais, beneficiando uma economia geográfica mais abrangente no território fronteiriço. Isto é interferir na dimensão produtiva das fronteiras.

Ficou faltando, até onde é possível observar, ao Projeto, mecanismos adequados de uma "construção de confiança" visando ao nascimento de ações associativas pontuais e/ou isoladas, suscitando um processo continuado de gestão coletiva progressiva, tornando factíveis, portanto, induções na esperança de coletivizar as responsabilidades ${ }^{30}$. Observa-se que, ao término do Projeto, ficou patente uma sensação de vazio, de ausência e de desorientação. Observa-se também que protagonismo do Sebrae foi de tamanha envergadura que não abriu possibilidades para que na sua ausência (f́́sica) a sua presença (exemplos) se fizesse sentida na direção da continuidade - neste sentido: uma perda.

Por tudo, todo o processo desenvolvido deixou marcas deléveis, mas antes que o tempo as apaguem requereria um esforço que caminhasse em outra condição, se não na direção contrária, mas no sentido diferente do que foi realizado: valorizar a interatividade territorial combinando ações coletivas, gerenciamento horizontal e o fortalecimento de práticas que proporcionem a expansão do conhecimento e aprendizagem de forma contínua e consistente - neste sentido: um desafio.

Não fica evidente que o caminhar do MS Sem Fronteiras tenha considerado, na sua execução, a ordem mundial, a conformação latino-americana e o processo de fronteirização nas duas conurbações de execução, fato não condenável por não se tratar de uma invernada acadêmica. Porém, não cabe a este estudo descartá-los, é possível definir ilações sobre eles e o objeto.

A fronteira do Brasil com a Bolívia está sob forte pressão do Corredor São Paulo-Santa Cruz, por onde transitam mais de U\$100 milhões/mês (fora o gás). Trata-se de uma "fronteira escolhida" para transação de mercadorias dentro do contexto do rebordering existente, com forte relação com o comércio export-import e com o setor mineral. Já a conurbação de Ponta Porã-Pedro Juan Caballero está ligada, indiretamente, ao Corredor Paranaguá-Asunción como axial de reexportação. Ambos os casos, estas redes econômicas, desdobram-se no território em formato de enclaves e exclaves econômicos específicos, robustamente decorrentes do nível e

${ }^{30}$ Poder de aglutinação e de "controle" do processo estava relacionada, majoritária e definitiva, à atuação do Sebrae/MS. 
do grau de interferência dos fluxos de capitais dados pela dinâmica (externalidades variantes) daqueles corredores e que, diretamente, se reportam ao comportamento da lógica conjuntural.

Considerando que as determinantes advindas da atual conjuntura brasileira (crise política e econômica), não é desconhecido que a reexportação está em baixa e as exportações estão favoráveis; desta feita, a fronteira de Corumbá com a Bolívia está, sob estes termos, se beneficiando mais do momento atual que a fronteira do Paraguai com Ponta Porã. Isto é, as intervenções paradiplomáticas de cooperação econômica provavelmente oscilarão, doravante, em conformidade com as dinâmicas sobrevindas deste arranjo.

O condimento Conformação Latino-americana é um assunto deveras apimentado ao cardápio fronteiriço. O evento da Bolívia ser um "Estado Plurinacional" (de direito e de fato) anima um conjunto de etnias com comportamento cultural e linguístico muito diversificado povoar a fronteira Brasil-Bolívia, bem como a produção de cocaína daquele país transforma a fronteira num caminho natural de passagem desta substância. Tanto um caso como o outro conecta a região a um circo desconcertante de atributos inverídicos, pobreza midiática e preconceitos a respeito dela.

$\mathrm{Na}$ fronteira do Paraguai, ao mesmo tempo, existem também grandes hiatos entre o comportamento dos ponta-poranenses e dos Pedro-juanuninos, contudo há que lembrar a presença de ambos submetidos à exploração da economia ervateira até a metade do século passado. Tal fato forçou-os à construção de pontes de aproximações e entrelaçamentos, facilitando, na atualidade, alguns propósitos de ajuntamento programático - uma grande vantagem. Porém, o Paraguai é o maior produtor de canabis da América do Sul ${ }^{31}$ e o maior fornecedor de cigarros para o contrabando, tornando toda fronteira sul do Mato Grosso do Sul submetida às diversas formas constrangedoras de descaminhos, contrabando, controle e vigilância comprometendo, como efeito, toda imagem daquele território.

Cada um destes e outros fatos, de modo geral e específico, interferem na composição orgânica do território, modelam por diversos meios a forma e a estrutura, interferem proporcionalmente na função socioeconômica e impõem limites

${ }^{31}$ Produção maior entre os Departamentos de Canindeyu e Amambay, ambos na fronteira com Mato Grosso do $\mathrm{Sul}$. 
às continuidades dos processos de articulação. Estas "deseconomias" e as externalidades negativas rebatidas nestas fronteiras são impossíveis de desconsiderá-las na consecução de projetos de qualquer natureza ${ }^{32}$. Não está posto nos documentos produzidos (nas Atas, sobretudo) pelo MS Sem Fronteiras elementos que alimentem comprovar uma atuação distinta dentre as ações desenvolvidas entre uma fronteira e outra - as ações foram cognatas - deixando margem à interpretação de que a dimensão sociocultural daquelas fronteiras não tenha sido considerada.

É sob a lume do Processo de Fronteirização que as intenções e iniciativas de acostamento - com ou sem formato paradiplomático ou com qualquer finalidade possui sua dimensão de tempo, propriedade, tamanho e continuidade definida. É o Processo de Fronteirização, a sua dinâmica, sua estatura e sua desenvoltura quem fornece instrumentos para quebrar as amarras derivadas da ambiguidade e da alteridade na materialização das ações cooperativas, como foi lembrado anteriormente. Em síntese, é este Processo que consolida o caráter dinâmico dos procedimentos socioespaciais adjacentes naquelas fronteiras.

Observando-se por um ângulo amplo, ambas fronteiras do MS Sem Fronteiras se beneficiaram deste Processo. O Projeto MS Sem Fronteiras navegou com certa tranquilidade sobre os ventos favoráveis soprados até recentemente, mesmo não se detendo aos processos históricos diferenciados. Mas: o Projeto foi suficientemente argucioso ao entender e aproveitar a dinâmica - mais proeminente no lado boliviano e paraguaio do que em relação ao lado brasileiro - para cumprir seus objetivos quantitativos.

\section{Contornando uma Conclusão definitiva}

No contexto deste estudo, a crise (econômica e política), enquanto fator conjuntural atual, fez com que os polos estabelecidos até recentemente como dinâmico e consorciado, tenham se cambiados densamente.

Tal modificação levou a um acrescentamento dos fluxos de bolivianos no lado brasileiro e a um arrefecimento das compras na Bolívia, fazendo que, na fronteira

\footnotetext{
32 Muito possivelmente, o Projeto MS Sem Fronteiras, embora não esteja documentalmente escrito, tenha sido pensado na probabilidade de se constituir em um "elemento reparador" dessa realidade.
} 
com a Bolívia, Corumbá passasse a assumir o papel de polo dinâmico, antes localizado no lado boliviano da fronteira. Já na Fronteira com o Paraguai, Ponta Porã era o lado que se beneficiava indiretamente das relações comerciais de reexportação de Pedro Juan Caballero; isto também se inverte, provocando um aquecimento do comércio na parte brasileira da conurbação e um maciço desemprego e fechamento de lojas na parte paraguaia ${ }^{33}$.

Notado isto, a configuração espacial daqueles territórios passam a requerer uma correção de rumo por parte dos "herdeiros" do MS Sem Fronteiras sob pena de perda prematura dos fatos ${ }^{34}$ - partindo-se do pressuposto que o Projeto ainda tenha forças para um caminhar sem auxilio externo.

A paradiplomacia, como aludido, nasce a partir de uma tessitura costurada por um conjunto de "mestres artesãos" da articulação territorial dentro de um processo intenso de relações de proximidade entre dois povos e, simultaneamente, estabelece elos agudos que podem se desdobrar em um aprofundamento das relações territoriais consolidadas ou em consolidação. Mas, muito a priori, os efeitos da paradiplomacia, executada, enquanto instrumento, está posta tête-à-tête a uma condição territorial já assentada: quanto mais forte é a aproximação territorial quão igualmente forte serão seus efeitos; assim como o inverso tenderá ser verdadeiro: quanto menor for a aproximação, menor serão os efeitos dos intentos paradiplomáticos.

Faz-se necessário observar, nesta probabilidade, que a paradiplomacia, como incentivadora de desenvolvimento, abstrai da condição imposta ao território (como resultado das práticas sobrevindas) os elementos que necessitam ser destravados mediante uma interlocução pactuada para o "fazer algo" em conjunto ou com o mínimo de contraposição. O que vale colocar em evidência que, para a paradiplomacia, com enfoque no desenvolvimento, a unidade elementar não é o indivíduo (ou instituição), mas sim a relação entre atores.

\footnotetext{
33 Segundo informações colhidas na Câmara de Comércio de PJC, mais de oitocentas lojas que vendiam produtos de reexportação foram fechadas em 2015, provocando o desemprego de mais de 1800 trabalhadores, mais da metade de brasileiras.

34 Considerando aqui que o Projeto foi armado e edificado sob o escudo de uma dinâmica territorial invertida àquela existente na atualidade.
} 
Assim posto, ainda que a pesquisa atual não tenha elementos substanciais para uma afirmação consistente e definitiva, em princípio, é possível erigir interpretações sobre a experiência exercida e o futuro do MS Sem Fronteiras.

Observado na perspectiva de possíveis desdobramentos de atuações paradiplomáticas no âmbito do desenvolvimento naquelas fronteiras, pode-se perceber:

Primeiro: que na conurbação Ponta Porã-Pedro Juan Caballero, o Processo de Fronteirização é muito maior e historicamente mais consolidado e deve produzir vantagens comparativas mais consistentes do que na semiconurbação de CorumbáPuerto Quijarro-Puerto Suarez (OLIVEIRA, 2015b), onde este Processo é historicamente mais recente e as relações por vários ângulos demostram ser muito embrionárias. Apenas de este fato coloca a dimensão territorial e a dimensão produtiva em patamares não congruentes entre as duas fronteiras.

Em termos abstratos, por mais paradoxal que possa parecer, a fronteira Brasil-Bolívia, por ter um Processo de Fronteirização menos consolidado, possui mais campo para dinamismo do que a fronteira Paraguai-Brasil. Verifica-se, por exemplo, que apesar de ser bem menor, o lado da Bolívia ${ }^{35}$ recebeu apoio a 292 empresas enquanto no lado do Paraguai ${ }^{36}$ foram 280 empesas beneficiadas. Mais ainda. O lado da Bolívia é o único das quatro partes que vem radicando uma continuidade do processo. Efetivamente, o projeto ali não parou ${ }^{37}$.

Segundo: com relação à Conformação Latino-americana, pela condição de ser (na ausência de outra palavra) introvertida, é pouco lembrada (inda que muito presente), convirá a ambas fronteiras na condição de enclaves sócio-estruturais de base rígida. Mormente, este não é um assunto que possa passar despercebido. Deve-se observar que a dimensão sociocultural entre as duas fronteiras é abismática; isto fez (faz e refaz) com que o modus operandi estabelecido (por qualquer projeto) requer considerações sobre o desnível existente. A multiculturalidade e a pluralidade étnica que povoam a fronteira Puerto Suarez,

\footnotetext{
${ }^{35}$ Com população inferior a 60 mil habitantes.

${ }^{36}$ Com população superior a 100 mil habitantes.

37 A HIVOS (Humanistisch Institut voor Ontwikkelingssamenwerking), holandesa, (com U\$ 180 mil) e a brasileira Votorantin (com U\$ 90 mil) aportaram na FTE-Fundación Trabajo y Empresa para dar consecução às ações estabelecidas pelo MS Sem Fronteiras.
} 
Puerto Quijarro e Corumbá, assim como dinamismo da economia boliviana ${ }^{38}$ têm sustentado - aqui alocada como hipótese - uma redução dos custos com a mão de obra, habitação, serviços, etc., na localidade, significando, em vários sentidos, manutenção dos fluxos de investimentos no lado boliviano como dito in nota 38 .

$\mathrm{E}$, terceiro: enquanto a fronteira paraguaia padece com o recrudescimento da reexportação, a fronteira de Corumbá com a Bolívia é sobrevivida com o aumento dos fluxos de exportação. A ordem mundial, na fronteira de Corumbá-Puerto Quijarro, enquanto "fronteira escolhida" pelo capital, constrói plausível prerrogativa sobre a fronteira Paraguai-Brasil, apoiando-se nas externalidades positivas do trânsito de capitais permitindo afixar outros nós de articulação.

De todo modo é que o Projeto MS Sem Fronteira foi uma experiência que não permite ser minimizada; nem o Sebrae/MS, enquanto autor da ideia e da execução, pode ser afastado (ou se afastar). Como todo projeto de intervenção social e produtiva, possui acertos e equívocos; com ele não foi diferente. O importante, entrementes, é estabelecer uma conexão entre o executado e o devir. Ou seja, é proeminente saber quais das atitudes implementadas serão capazes de construir continuidade na mesma ou em perspectiva diferente.

Em resumo final, pode-se afirmar que: enquanto instrumento paradiplomático, não requer dúvida de seu sucesso, e sobre este esteio não se deve perder a oportunidade de um aprofundamento pragmático por parte das comunidades envolvidas; sob o aspecto do desenvolvimento, a sua contribuição tem aparência momentânea, pontual e dependente da dimensão produtiva territorial. Fatos que permitem uma continuidade.

\section{Referências Bibliográficas}

BOISIER, S. (2001), Desarrollo (local): ¿de qué estamos hablando? Estudios Sociales, VARQUEZ BARQUERO, A. y MADOERY, O. Rosario: Homo Sapiens Edições, 2001. Disponível em: http://abacoenred.com/IMG/pdf/boisier.pdf. Acesso em: 29 abr. 2015.

\footnotetext{
38 De 2007 a 2015, a expansão anual média do PIB no país foi superior a 5\%, com baixa inflação e com políticas sociais suscitando forte distribuição de renda, atraindo investimentos estrangeiros e produção de riqueza.
} 
BOISIER, S. (1999), Post-Scruptum sobre desenvolvimento regional: modelos reais e modelos mentais. Planejamento e Políticas Públicas, Brasília, n. 19, p. 307-343, jun.

BORDIEU, P. (2005). O campo econômico. Política \& Sociedade, 6: 15-58

BORDIEU, P. (2001). Meditações pascalinas. Rio de janeiro: Bertrand Brasil.

CORNAGO PRIETO, N. (2004). O outro lado do novo regionalismo pós-soviético e da Ásia-Pacífico: a diplomacia federativa além das fronteiras do mundo Ocidental. In: VIGEVANI, T; WANDERLEY, L. E.; BARRETO, M. I. e MARIANO, M. P. (orgs.). A dimensão subnacional e as relações internacionais. São Paulo: Editora PUC/Editora UNESP/CEDEC/FAPESP.

DUCHACEK, I. D. (2001) Perforated Sovereignties: Towards a Typology of New Actors in International Relations. In: MICHELMANN, H.; SOLDATOS, P. Federalism and International Relations. The role of subnational Units. Oxford: Clarendon Press.

FALCÓN, L. G. de C.; JARA, A. C. (2005) Cooperativas y desarrollo local participativo. Interações v. 7, n. 11, mar, p. $25-32,2005$.

GALÁN, M. G.; PINO, B. A.; CALVO, M. A. Reflexiones práticas sobre cooperación triangular. Fundação CIDEAL de Cooperação e Investigação, Espanha, ISSN14154765,.Disponível

em:

http://www.cideal.org/docs/COOP\%20_TRIANGULAR_OnLine.pdf. Acesso em: 03 mar. 2015

GALLICCHIO, E.; CAMEJO, A. (2005) Desarrollo local y descentralización en América Latina: nuevas alternativas de desarrollo. Montevideo, Uruguay, Centro Latinoamericano de Economía Humana (CLAEH), Diputación de Barcelona. 183 p.

GRINSON, A. (2003) Los processos de fronterización: flujos, redes e historicidade. In: GARCIA, C.I. Franteras: Teritorios y Metáforas. Medelin: Hombre Noevo Editores INOJOSA, R. M. (1999). Redes de compromisso social. RAP: Rio de Janeiro, (5) 115.41, Set/Out.

MARTÍNEZ, O.J. (1994) The dynamics of border interaction. In SCHOFIELD, C. H. Global boundaries. World boundaries. London/NY. v.1 pp.1-15.

MATO GROSSO DO SUL. - SEMAC e SEPROTUR. Plano de Desenvolvimento e Integração da Faixa de Fronteira/MS. Disponível em: [http://www.semac.ms.gov.br/controle/ShowFile.php?id=120791]. Acesso em: 14 ago. 2015.

NEWMAN, D. (2006) Borders and Bordering. Toward na Interdisciplinary Dialogue. European Journal of Social Theory, SAGE Publication, v. 9, n. 2, pp 171-186

ODONNE, N.; VÁZQUEZ, H. R. Cross - border cooperation in Latin America. In: PRADO, H. S. A.; ESPÓSITO NETO, Tomaz (org.). Fronteiras e Relações Internacionais. Curitiba: Ithala, 2015.

OLIVEIRA, T.C.M (2012). Participação e desenvolvimento na fronteira BrasilParaguai - um exemplo. In: MELLO, S.P.T Administração Pública Contemporânea: Temas para o debate. Pelotas: Editora da UFPel. 
OLIVEIRA, T.C.M (2015a). Para além das linhas coloridas ou pontilhadas - reflexões para uma tipologia das relações fronteiriças. Revista da Anpege.p.233-256, V.11, n.15, jan-jun.2015.

OLIVEIRA, T.C.M; ESSELIN, P. M. (2015b). Localizando as condições pretéritas e as relações correntes na complexa fronteira Brasil-Bolívia. Revista Geosul. Florianópolis, v. 30, n. 60, p 125-163, jul./dez.

PAQUIN, S. (2004) Paradiplomatie et relations internationales: théorie des stratégies internationales des régions face à la mondialisation. Bruxelles: Presses Interuniversitaires Européennes. P.I.E. - Peter Lang SA. Disponível em: http://www.crepic.enap.ca/CREPIC/Publications/Lists/Publications/Attachments/49/P aradiplomatie\%20et\%20relations\%20internationales.pdf. Acesso em: 10 mar. 2015.

PÈBAYLE, R. (1994) As regiões de fronteira e o projeto de integração no Mercosul in: LEHNEN, A et. Al (Org) Fronteiras do Mercosul. Porto Alegre: UFRGS.

PINO, B. A (2013). A Cooperação Triangular e as Transformações da Cooperação Internacional para o Desenvolvimento. IPEA. Texto para Discussão 1845.

RÜCKERT, CAMPOS, SUPERTI E PORTO (2014). Transfronteirizações na América do Sul: uma agenda de pesquisa sobre dinâmicas territoriais nas fronteiras meridional e setentrional do Brasil. Revista Eletrônica de Humanidades do Curso de Ciências Sociais. UNIFAP. v.7 n. 1, p. 99-115, jan.-jun.

RIBEIRO, M. C. M. (2009) Globalização e novos atores: a paradiplomacia das cidades brasileiras. Salvador: Universidade Federal da Bahia. Disponível em: https://repositorio.ufba.br/ri/bitstream/ri/12065/1/globalizacao-e-novos-atores_ri.pdf.

Acesso em: 10 mar. 2015.

RÜCKERT, CAMPOS, SUPERTI E PORTO (2014). Transfronteirizações na América do Sul: uma agenda de pesquisa sobre dinâmicas territoriais nas fronteiras meridional e setentrional do Brasil. Revista Eletrônica de Humanidades do Curso de Ciências Sociais. UNIFAP. v.7 n. 1, p. 99-115, jan.-jun.

SANGUIN, A. L. (2015). Paisagens de fronteira: variações em um importante tema da geografia política. Boletim Gaúcho de Geografia. v. 42, n.2 - págs. 389-411 - Maio.

SEBRAE.(2006) Gestão Estratégica Orientada para Resultados: avaliação e desafios. Brasilia: Editora SEBRAE.

TORRE, A. 2003 "Desenvolvimento Local e relações de proximidade: conceitos e questões" Revista Interações, V.4. N.2. Campo Grande: UCDB.

Recebido em 10 de setembro de 2017. Aprovado em 11 de dezembro de 2017. 